\title{
Santiago Pavlovsky
}

Jorge H. Milone

President, Sociedad Argentina de Hematología
Submitted: $12 / 27 / 2010$

Accepted: 12/28/2010

Correspondence: Jorge $\mathrm{H}$. Milone Sociedad Argentina de Hematología Julian Alvarez 146 - Ciudad Autónoma de BS As - Argentina

Phone: 54114855 2452/2485

itno@netverk.com

www.rbhh.org or www.scielo.br/rbhh

DOI: 10.5581/1516-8484.20110021

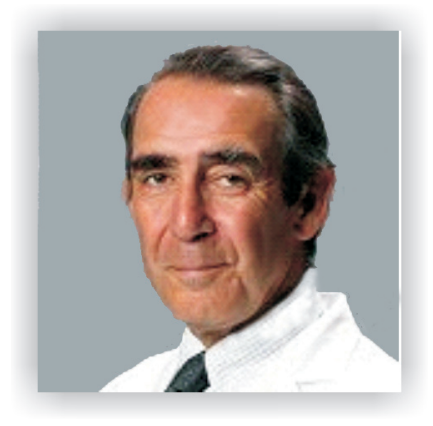

A tireless worker, he promoted clinical research in Argentina and was well aware of how to accomplish and transmit warmth in medical treatment and excellence in scientific production to his disciples.

Born into a family of outstanding hematologists, Santiago graduated as a Medical Doctor at the University of Buenos Aires in 1964, and completed his postgraduate degree at the Hospital Saint Louis of Paris with Professor Jean Bernard.

Once he returned to Argentina, after working at the Instituto de Investigaciones Hematológicas, Academia Nacional de Medicina, he created the GATLA, Argentine Group for the treatment of Acute Leukemia, a pioneering group in clinical research in Latin America, through which he made innovative worldwide contributions about Hodgkin's disease; improving care of patients in our country through the creation of treatment protocols.

From 1983 to 1986, he coordinated from Washington the Collaborative Cancer Treatment Research Program of the National Cancer Institute and the Pan American Health Organization.

He was a Coordinator of International Affairs for the American Society of Clinical Oncology (ASCO) and the European School of Oncology.

Since 1989, he was the medical director of Fundación para Combatir la Leucemia (Fundaleu), and then the scientific director.

Doctor Pavlovsky was an outstanding scientist, who was a member of the most important medical societies of his specialty in the world.

He published 144 scientific papers and 76 book chapters.

He was "Physician of the Year" in 2000.

Disregarding his high academic level, he always managed to be not only side by side with his patients at his practice or through hospitalization, relieving and curing them, but also with his colleagues and disciples, encouraging them to continuously surpass the struggle against malignant hemopathies.

He died last September $19^{\text {th }}$. The Argentinean hematological community will always remember him as one of the special figures in the development of the specialty. 